\title{
A CHAT APPROACH TO UNDERSTAND FRAMING IN DIGITAL SERVICE INNOVATION
}

\author{
Sturkenboom, Nick (1); Baha, Ehsan (1,2); Price, Rebecca (1); Kleinsmann, Maaike (1); Snelders, \\ Dirk (1)
}

1: TU Delft; 2: Meaningwise

\begin{abstract}
Within the third wave of digital service innovation, framing is becoming increasingly complex. Accordingly, design practice finds itself in a transition from designing single service solutions that are shared, to designing systemic solutions that are shareable. We report a case study in which we use Cultural Historical Activity Theory (CHAT) to analyze the framing process that a designer went through when designing a digital service for a Connected Care startup. Results show the importance of the designer's activity awareness and the challenge of dealing with relational complexity when framing the digital service innovation. With this work, we hope to inspire researchers and practitioners with the potential that CHAT has to offer for the reflective practice in digital service innovations.
\end{abstract}

Keywords: Service design, Design theory, Design practice, Reflective Practice, Cultural Historical Activity Theory

\section{Contact:}

Sturkenboom, Nick

TU Delft

Product Innovation Management

The Netherlands

n.sturkenboom@tudelft.nl 


\section{INTRODUCTION}

This paper focuses on how Digital Service Innovation (DSI) can point to new ways of considering the role of framing in design, i.e. the way designers structure their beliefs, perceptions, and appreciations within problem and solution spaces (Schön and Wiggins, 1992). In design, framing was originally introduced by Donald A. Schön, as a reflection about the context of a particular action, or "a setting of some problems to be solved" (Schön, 1984, p. 132). This and later works of Schön opened the agenda for a phenomenological epistemology of design practice for tackling issues of complexity in a way that deviates from technical rationality. His legacy demonstrates how designers engage in a reflective conversation with the situation at hand, based on previous experience. In response, the design research community started applying his work to more psychological and social processes. As a result, research on framing developed further with key contributions, among others, on: cognition (Akin, 2001; Cross, 2001; Lloyd et al., 1995), reasoning (Cross, 2007; Dorst, 2011, 2015; Dorst and Cross, 2001), and the representation of knowledge in design (Goldschmidt, 1991; Stompff, 2012). In this effort, there has been a growing recognition of the complexity of the design process, especially in relation to designing in teams, and of the role of design in stakeholder collaborations (e.g. Hey, 2008; Kleinsmann, 2006; Valkenburg, 2000; Stumpf and McDonnell, 2002).

Over the last decade, design practices have become even more complex than before, due to the influence of the so-called 'third wave' of (DSI) (Yoo et al., 2012). Within the third wave of DSI, design practices have increasingly become socially embedded in networks where actors both produce, consume, exchange, and distribute value. DSIs address various, often unforeseen needs, bringing open-endedness to the design and development for digital platforms. Data is the main material for DSI, accessible to all network actors (including designers) via connected digital devices (Barrett et al., 2015).

The increased complexity of the context of design in DSI (from an established team to an open network) is having consequences for the design process itself. In this paper we focus on the particular challenge that DSI poses on our understanding of framing in design, especially with respect to collaboration between network actors. As a consequence of DSI, design practices are shifting focus from creating singular stand-alone services to creating platforms that are always in a state of transition (Calabretta and Kleinsmann, 2017; Kleinsmann and Snelders, 2015). While in transition, the platform becomes interesting for new service providers to connect to; creating cascading effects - innovations that strengthen other innovations (Boland et al., 2007).

For example, with its design of a new hospitality service, AirBnB intently reframed and disrupted the tourism industry by introducing a notion of 'sharing' into a traditional frame of 'hosting'. However, their platform not only reframed the relationship between a BnB owner and a tourist, AirBnB also had to become sensitive to its connectedness to tour guides and travel apps. Moreover, AirBnB's growth has been causing disruptions on the housing market and decreased livability in some cities, to which local municipalities have started to respond to by imposing regulations that limit AirBnB's business model (Kimbell and Blomberg, 2017). These effects, many of them unintended and unforeseen, are posing significant challenges to the design process, among others in how its targets are in a constant state of flux, and how this forces designers to address the needs and competences of a heterogeneous set of actors in an open-ended network.

The AirBnB case demonstrates how new designs for DSI require careful thought about the involvement of unforeseen actors and activities that unfold over time. A consequence for the design process for DSI is that designers should no longer strive towards a stable, consensual solution, as a compromise between co-creative design team members. Instead, what is unfolding within DSI is a careful collaborative reflection with potential network partners on how to create an inviting platform to deliver value to a wide range of potential users and co-producers. In other words: in DSI the design process moves from targeting consensual, 'shared' solutions among pre-existing team members to 'shareable' solutions for potential adopters and adapters of the DSI.

Returning to the issue of framing, we propose that a frame is best approached within DSI by thoroughly understanding the relational dynamic between multiple social and technical perspectives that exist in a network. Designers can approach this relational dynamic by studying the current, and envisioning potential future activities of potential network actors. By 'activity' we mean an "artifact-mediated and objectoriented action", (Vygotsky 1978, p. 40), a central concept in a larger theory called Cultural Historical Activity Theory (CHAT). CHAT describes activities as evolving systems of intentions towards subject, 
object, instruments, and social embeddedness, see Figure 1 (Engeström 2014). In other words, we understand any activity of a network actor (designers included) as a subject embedded in a social situation, and using instruments (tools, signs) to contemplate what object they are trying to achieve; a reflective conversation that is inherently cognitive, mediated by materials, socially embedded, and processual.

In some applied models of CHAT, activity awareness is seen as an important means for network actors to approach and appreciate other actors together with their intentions (Carroll et al., 2006). For designers in DSI, activity awareness helps for studying and envisioning reconfigurations of materially and socially embedded activities in an evolving, open-ended network of actors. In this sense, every instance of activity awareness should be seen as indicative of a frame, which within CHAT we have to define as an intentional kind of seeing. It implies that frames are a mode of problem setting that is always personal (yet shareable), and that cannot be offered for neutral analysis with others. This suggests that CHAT can assist designers in DSI to see and draw out a relational dynamic between multiple actors in a network, and help to understand deeper meanings behind the different perspectives, identify potential partners, consider physical and digital materiality in the network, and envision, test, and coordinate when and where service interactions could occur. This assistance to designers for DSI has already been noted for the design of service innovation, where a number of first attempts have been reported in applying CHAT to service design (e.g., Maffei and Sangiorgi, 2006; Menichinelli, 2018), and digital innovation, where CHAT has been applied in interaction design (Kaptelinin and Nardi, 2009; Kaptelinin and Uden, 2012).

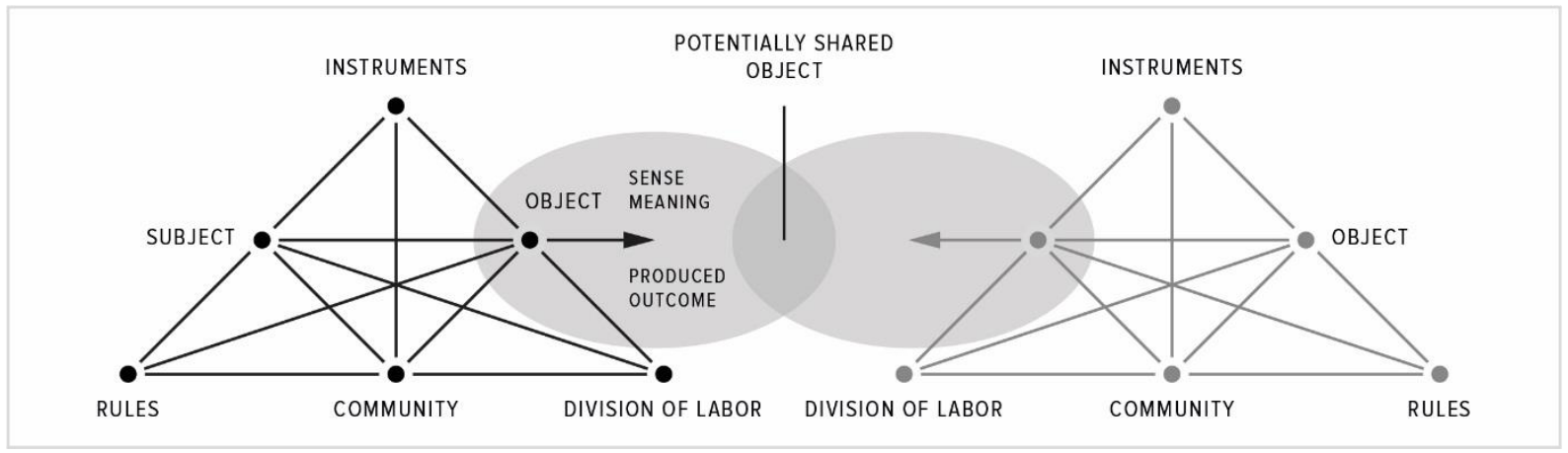

Figure 1: 2 interacting activity systems, adopted from Engeström (2014, p. 305).

We argue that framing in DSI should be approached as a designer's intention that is indicated by an 'activity awareness' that is fed by (and feeds back to) a process of co-reflection with potential network actors (for co-reflection, see Yukawa, 2006; for the use of co-reflection in design projects see Baha, 2010; ten Bhömer, 2016; to read more on the development of designers' intentions see Baha et al., 2018). This implies that, in order to render novel and appropriate interventions, the design of DSI requires a thorough awareness of activity systems, and the deeper relationships that run within and between them. To investigate a co-reflective approach to framing within DSI, we report on a case study of a designer working for a connected care startup. We identify activity awareness from a designer over the course of his design process, mainly by analyzing drawings and notes in the designer's project notebook. In the analysis we searched for sequences of seeing-moving-seeing, which in Schön's work were either thought to reside in frames, or be intuitions for frames (Schön and Wiggins, 1992). Our case study shows an activity awareness that is in constant flux, with different (combinations of) activity systems represented over the course of the design process. We see this as indicative of how the designer moves between different frames, in order to design a novel and open solution for a heterogeneous set of network actors.

\section{RESEARCH DESIGN AND METHODOLOGY}

\subsection{Case study approach}

An instrumental case study methodology (Creswell, 2012) is reported to provide an explorative method for looking at how a designer becomes aware of different activity systems, how this awareness influences the foci of the DSI framing design process, and how CHAT may be used for design in DSI. The reasons for case selection are threefold. First, the project was considered an exemplary success of a DSI by the authors and the original client. Second, the designer had a high level of mastery of 
sketching and using that to document his thoughts and communicate with others; The designer's sketches and notes are used as the main data source for this research. Finally, in the project a reframing of the brief occurred, triggered by a newfound appreciation of the project context.

\subsubsection{Case, context, and actors involved}

The context of this research was a 6-month MSc graduation project of an industrial design student with +5 years working experience, henceforth 'the designer'. The client was a Connected Care startup. Running since 2009 , the startup has been offering a self-healthcare solution for managing a sleep disorder. In 2017, the 25+ employees sized company was operating in 10 countries before it was acquired by a global electronics company 1 year later. The designer enjoyed supervision from 2 university mentors ( 1 being the first author), the CEO, and the startup's lead designer.

The project's initial brief was to improve patient compliance to the startup's digital service. The client had identified usability issues of their device as the main problem for patient compliance. A higher patient compliance was important to the startups efforts in obtaining insurance coverage for people using the service. The client's research indicated that their users had difficulties in understanding how and when to upload their data. Other problems that the company had identified were that people were not gaining sufficient insights from service, partially because they didn't properly upload their data. The start-up hauled gamification as the solution to the identified problems.

\subsubsection{Data collection}

Table 1 shows the 3 types of data that were collected throughout the design project. The first source exists out sketches and notes from chronologically recorded project notebook of the designer. In this notebook, the designer creatively expressed and explored various ideas through text and sketches, which indicate acts of reflection in- and on action. The expressions ranged from analytic endeavors (e.g. understanding project objectives and design context, internalizing newfound knowledge) to synthetic expressions (setting project boundaries, indicating opportunities for innovation, proposing new concepts). The other sources were used for triangulation, allowing us to retrace and reflect on what happened during the project and when, as a significant part of the notebook pages and all other files were marked by date. We would like to highlight that the designer was not instructed to keep a project notebook in any way. Sketching was his preferred way of tinkering and communicating to others. Because of his skills and careful documentation of his own thoughts, the notebook was selected as the appropriate data source to reveal the designer's process of seeing and reasoning throughout the project.

Table 1: Overview of the data collection.

\begin{tabular}{|l|l|l|l|}
\hline Data & Source & Form & Reflection \\
\hline $\begin{array}{l}\text { First person (designer) } \\
\text { perspective of the DSI } \\
\text { framing process. }\end{array}$ & $\begin{array}{l}\text { The designer's } \\
\text { project notebook. }\end{array}$ & $\begin{array}{l}\text { 200 pages of chronologically } \\
\text { ordered visual and textual } \\
\text { documentation. }\end{array}$ & $\begin{array}{l}\text { Reflection in/on } \\
\text { action by the designer. }\end{array}$ \\
\hline $\begin{array}{l}\text { Eliciting and } \\
\text { addressing progress } \\
\text { and challenges. }\end{array}$ & $\begin{array}{l}\text { Project coach } \\
\text { meetings. }\end{array}$ & $\begin{array}{l}\text { Audio recordings of 8 one-hour } \\
\text { coach meetings. }\end{array}$ & $\begin{array}{l}\text { Reflection on action } \\
\text { by the designer and } \\
\text { project coach. }\end{array}$ \\
\hline $\begin{array}{l}\text { Rationale and details } \\
\text { of the DSI framing } \\
\text { aspects and process. }\end{array}$ & $\begin{array}{l}\text { Presentation } \\
\text { slides and final } \\
\text { report. }\end{array}$ & $\begin{array}{l}\text { 5 sets of slides, 109-page } \\
\text { report, 59-page appendix, and a a } \\
\text { reflection on action essay. }\end{array}$ & $\begin{array}{l}\text { Reflection on action } \\
\text { by thesigner and } \\
\text { supervising team. }\end{array}$ \\
\hline
\end{tabular}

\subsubsection{Data analysis}

The coding of frames is usually based on Schön's theory of reflective practice, with an established data analysis method based on the identification of action frames from a design team's verbal communication (see e.g. Valkenburg and Dorst 1998, Stumpf and McDonnell 2002, Kleinsmann et al., 2012). In contrast, here we take as our main data sequences of seeing-moving-seeing (Schön and Wiggins, 1992), together with the designer's written reflections of his activity in the notebook (with further triangulation with audio recordings of coach meetings and presentation slides and reports). A 
first justification of turning to an analysis of sketches as externalizations of thought is found in Lloyd et al. (1995), who point out that talking limits the ability to frame. Another important reason for us to opt for a primarily visual analysis of framing is that we wanted to relate framing activities to CHAT (Engeström 2014). Based on CHAT, our main interest should be in the designer's visual synthesizing efforts to describe current and potentially new activity systems. Moreover, CHAT is more interested in the intentions with a move in a frame (as a way of seeing), than in a reflection on the consequences of that move in the frame (which focuses more on the Deweyan notion of a 'problematic situation').

In particular, we identify activity systems by looking at and inferring to what the designer sees as the design space (who is/are the subjects?); what different social and material aspects and relationships is he paying attention to? Activities may happen on different planes, ranging from a single activity from an intrapersonal (individual) perspective, to a plane of networked activities (groups and swarms), and form part of the material that a designer needed to work with in a DSI. For example, the designer sees a tension between the sales channel of the startup (subject) and the interests of insurance companies. The startup needs to comply to demands of the insurance companies in order to obtain coverage for patients. The startup considers a range of objects in mind that determine the activity (e.g. increasing service compliance to obtain lower prices by improving user experience in order to sell more units).

The aim here has been to retrieve activity systems to indicate awareness of these elements over time, in first instance as intentions to enable effective moves in a complex (cultural historical) context, rather than as social positions that are supportive or critical of specific design moves.

The data analysis occurred in 5 steps, as per Table 2. Open coding between two coders provided an avenue to identify seven separate activity systems (Steps 1-2). Additionally, to test for the trustworthiness of coding, 20 samples from the notebook were taken and coded independently by two raters, now using the classification of the seven activity systems identified earlier. Within the 20 samples Rater 1 found 36 systems, vs 28 systems by rater 2 ( $28 \%$ difference). From the 28 systems identified by Rater 2, only one system had been classified differently by Rater 1 . Thus, the main basis for error in the data seems to be based on the recognition of an activity system, and not on the classification of that system. Given that earlier two researchers had been collaborating to build the classification scheme, such a recognition error is likely to have played a minor role during coding. For Step 3, we visualize a timeline to provide a processual overview of the DSI framing process. In Step 4, we additionally coded when activity systems were considered by the designer during the project. Finally, in Step 5 a post-hoc reflection was made by the first two authors as a preparatory step for writing this paper.

Table 2: Overview of the 5 steps for data analysis.

\begin{tabular}{|l|l|}
\hline (Step) Objective & Description \\
\hline (1) Develop a coding scheme. & $\begin{array}{l}\text { Obtain all revealed activity systems within the design project and } \\
\text { construct a coding scheme accordingly. The designer's notebook } \\
\text { was used as the main data source and triangulated with other } \\
\text { sources to reach an agreement, see Table 1. }\end{array}$ \\
\hline (2) Code main activity systems. & $\begin{array}{l}\text { Initially, the designer's project notebook was individually coded } \\
\text { in an open way by two researchers. Results were then compared } \\
\text { and iterated upon, leading to seven separate activity systems. }\end{array}$ \\
\hline $\begin{array}{l}\text { (3) Visualizing the framing } \\
\text { process by means of occurrences } \\
\text { within the designer's notebook. }\end{array}$ & $\begin{array}{l}\text { Composing a visual overview of how many times the designer } \\
\text { attended to elements within the different activity systems in his } \\
\text { notebook (Figure 2). }\end{array}$ \\
\hline $\begin{array}{l}\text { (4) Counting activity systems } \\
\text { occurrence and pages spend. }\end{array}$ & $\begin{array}{l}\text { Constructing a table with number of pages used for an activity } \\
\text { system within the designer's project notebook. }\end{array}$ \\
\hline $\begin{array}{l}\text { (5) Reflecting on the DSI } \\
\text { framing process of the designer } \\
\text { in relation to the project } \\
\text { progress and outcomes. }\end{array}$ & $\begin{array}{l}\text { The reflections were performed with the following topics in } \\
\text { mind: considerations the designer made during the project } \\
\text { process, identification of new opportunities, the designer's } \\
\text { struggles, and the change of frames considered over time. }\end{array}$ \\
\hline
\end{tabular}




\section{RESULTS}

\subsection{The revealed activity systems}

Analysis of the design journal identified of 7 activity systems, presented and labelled in Table 3.

Table 3: Overview of activity systems that were discovered and used to analyse.

\begin{tabular}{|l|l|}
\hline Activity System & Description \\
\hline $\begin{array}{l}\text { Design Project } \\
\text { (DP) }\end{array}$ & $\begin{array}{l}\text { The project assigned to the designer. Within this activity system, the designer } \\
\text { made moves in preparing himself for meetings, reflecting on what to include or } \\
\text { highlight in presentations, and who in the supervising team wanted what. }\end{array}$ \\
\hline $\begin{array}{l}\text { Digital Service } \\
\text { (DS) }\end{array}$ & $\begin{array}{l}\text { The current connected care service. The designer would look at the current } \\
\text { strengths and weaknesses within the device-user-client relationship. }\end{array}$ \\
\hline $\begin{array}{l}\text { Connected Care } \\
\text { (CC) }\end{array}$ & $\begin{array}{l}\text { The broader 'genre' of connected care. The designer considered and learned } \\
\text { from other connected care solutions, their histories, ideas, and goals of connected } \\
\text { care in order to discover, analyse, understand, and form opinionated judgements } \\
\text { for his own context. }\end{array}$ \\
\hline $\begin{array}{l}\text { Startup } \\
\text { (S) }\end{array}$ & $\begin{array}{l}\text { The project client. Various elements and perspectives of the company were } \\
\text { explored. E.g. its history, routines, objectives, and interactions with company } \\
\text { stakeholders that would allow them to reach their objectives and maintain a } \\
\text { growing form of business. }\end{array}$ \\
\hline $\begin{array}{l}\text { Patient } \\
\text { (P) }\end{array}$ & $\begin{array}{l}\text { The 'end-user'. The designer learned about their personal history, experience } \\
\text { with the disorder, attitudes to the connected device, and how other mediators } \\
\text { (e.g. newfound strategies, communities, family, their doctor) are related in } \\
\text { managing the disorder. }\end{array}$ \\
\hline $\begin{array}{l}\text { Doctor } \\
\text { (D) }\end{array}$ & $\begin{array}{l}\text { The medical specialist(s). The designer looked at how the DSI might support } \\
\text { current routines, open new possibilities, and increase its relevance to patient and } \\
\text { specialists. }\end{array}$ \\
\hline (DSI) & $\begin{array}{l}\text { The newly envisioned digital service which re-configures elements from existing } \\
\text { activity systems and sets out to expand the overarching activity by seeing how } \\
\text { identified activity systems may benefit. Once the requirements and design were } \\
\text { formulated, the designer presented a design for an open-ended platform for the } \\
\text { startup, with service features that co-benefit current and future actors. }\end{array}$ \\
\hline
\end{tabular}

\subsection{The digital service innovation framing}

The design journal was coded from beginning to end, using codes from Table 3. Figure 2 illustrates the DSI framing process of the designer as a processual overview. Annotations are made as part of the analysis and elaborated in the findings (Section 5). In Figure 2, the activity systems are communicated with the abbreviation of the codes from Table 3. Behind each activity system code, there is the number of occurrences that the activity system appeared within chronological design journal, followed by the percentage of space occupied in terms of pages. The darker the gray shade boxes, the more occurrences. Furthermore, through dotted lines, the DSI framing process is divided into 4 framing phases (A, B, C, and D). Next, the overlaying highlights are used to indicate the simultaneous consideration of multiple activity systems during the DSI framing process. The darker these highlights, the more activity systems, with 2 activity systems as minimum for the existence of a combination. Under each highlighted instance are 2 numbers where the first indicates the multiple activity system consideration instance and the second (in superscript) the number of activity systems that are simultaneously considered. Finally, highlights are drawn out from the Design Project (DP) activity system to illustrate that this activity system was considered mostly in isolation, except the very end of the DSI framing process. 


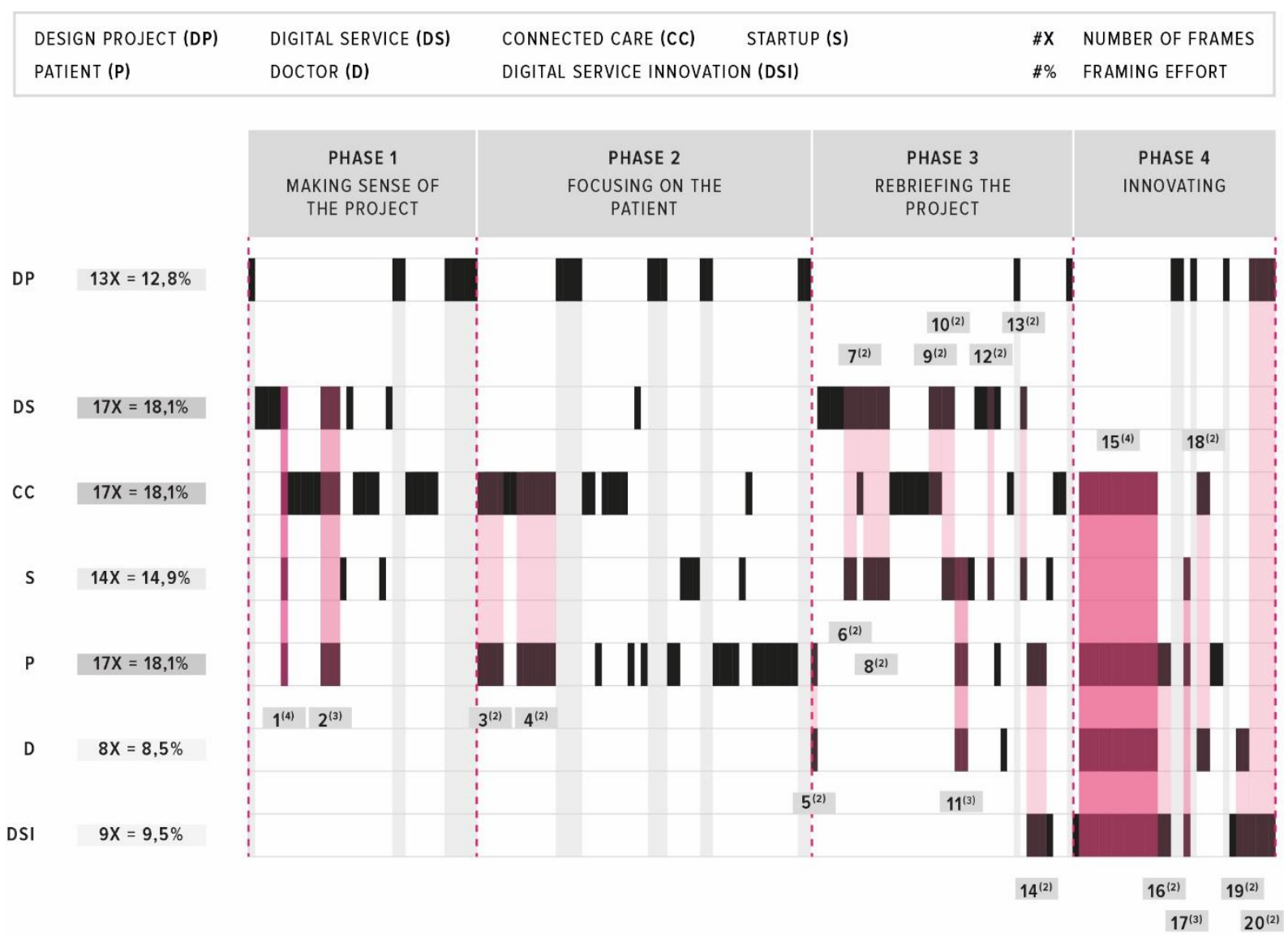

Figure 2: Annotated illustration of the DSI framing process.

\section{FINDINGS}

\subsection{The DSI framing phases}

The DSI framing process of the designer can be divided into the following 4 phases (Figure 2):

\subsubsection{Phase 1: making sense of the project}

In the first phase, the designer's focus was to make sense of the project. This is evident from the designer's focus on ready at hand activity systems, see combinations of DS, CC, S, and P with DP in isolation (Figure 2, phase 1). Sensemaking of the context is made evident by the parallel exploration of activity systems, initiated by the existing digital service of the startup (frames 1 and 2).

\subsubsection{Phase 2: focusing on the patient}

In the second phase, the designer's focused on the project using a human/user-centered approach, involving co-reflective sessions to engage upon the lifeworld of various actors. The human-centered approach is evident from the number of Patient $(\mathrm{P})$ frames (8) that are occurring in phase 2. The understanding of the user and design moves made in this activity system is done in combination with considering and comparing existing solutions in the market (frames 3 and 4). The designer's activity awareness here was limited by the client's view (human/user centered) of the project.

\subsubsection{Phase 3: rebriefing the project}

Using insights gained from the first 2 phases of the project, the designer went back to reflect on the initial design brief proposed by the client. This is evident from the number of frames in this phase (frames 6, 7, $89,10,12$, and 13). Moreover, the designer starts working towards a digital service innovation (See frame 14) by reframing the initial brief (frames 5 to 13) by including and relating to other actors such as the doctor (a.o. frames 5 and 11). 


\subsubsection{Phase 4: innovating}

Phase 4 starts with a creative burst (frame 15), right after the reframing of the brief and initial design direction (frame 14) was accepted by the client and supervising team. Notable here is the synchronization between Connected Care (CC), Patient (P), Doctor (D), and Digital Service Innovation (DSI) (frame 15). The digital service innovation was further detailed to suit the client (frame 17), other actors and the doctor in particular (frame 18), and later revealed to the client and project mentors by a final presentation (frame 20).

\subsection{The DSI framing process}

Investigation of the designer's DSI framing process with a CHAT approach results in 4 main findings:

\subsubsection{Framing constrained by the client's framing}

The designer's framing process shows that his activity awareness was initially constrained by the client's framing in the project brief. Figure 2 shows that initial framing attempts (phase 1 and 2 of the project) are based on a user/human-centered design approach with the focus on the patient (P). Subscribing to the client's brief, the designer focused on the client's current digital service (DS) and familiarized with digital services of other service providers (CC), and reflected on what they could mean to the patient (P). Looking at the designer's framing process as a whole reveals the user/humancentered approach by simply counting the occurrences of systems. Looking at Figure 2, connected care (CC), patient (P) and digital service (DS) form the majority of frames (see the \% at the left). Additionally, the notebook reveals early explorations of digital technology possibilities within connected care (CC). These were discarded due to the limited resources available in the startup.

\subsubsection{The design project, a blind spot in framing}

The activity-based analysis highlighted another important driver of the framing process, i.e. the design project (DP) itself. Notable about this activity system is that the design project (DP) is always addressed in isolation (Figure 2, shaded extensions of the (DP) frames), except at the very end of the project where design project (DP) and digital service innovation (DSI) are addressed simultaneously (frame 20). The project (DP) functions as a driver for consolidating different frames in an effort to process complexity, a moment of reflection on action, planning and aligning to the expectations of the project team.

\subsubsection{Muddling through, but only with 2 activity systems in a frame}

Within the framing process, separate activity systems are regularly considered simultaneously (Figure 2, frame 1 to 20). These considerations range from 2 to 4 activity systems. From the 20 simultaneous considerations, only 2 times, 4 activity systems were considered (Figure 2, frame 1 and 15); only 3 times, 3 activity system were considered (Figure 2, frame 2, 11, and 17); 15 times, 2 activity systems were considered (Figure 2, frame 3-10, 12 to 14, 16, and 18 to 20). The designer usually considered only 2 activity systems simultaneously when framing. Complexity was reduced by framing compartmentalized activities of the system; for example, synthesizing patient (P), connected care (CC) and digital service (DS) aspects only. These moments of synthesis were followed by a return to evaluate progress against the design brief, before the designer stepped back into the Patient or Startup related activity systems. Norman and Stappers (2015) describe this kind of journey through a system as 'muddling through' in an effort to understand without becoming overwhelmed by complexity. The designer mentions in the reflections that he often felt overwhelmed by the complexity of the project but that his ability to visualize new concepts helped him in coping with that complexity and supported communicating his ideas to others when co-reflecting.

\subsubsection{The significance of activity awareness for framing in DSI}

2 activity systems were revealed late in the framing process: The doctor (D) and the digital service innovation (DSI); The doctor's input became vital to progress at this point. Frames developed in the early phases seemed to reinforce the design brief that focused on a self-care solution for patients. As a result, the doctor was initially overlooked as it was framed only as part of the sales channel by the client. By bringing in the doctor's object in the project, the designer was able to evaluate and reframe the project brief, indicated by the sudden back and forth switching before synthesizing the DSI concept (Figure 2, phase 3). This awareness enabled the designer to move beyond the initial fixation 
on patient-centered care and consider perspectives from other actors for the digital platform. The doctor (D) stood out as an actor who could positively contribute to the patient's experience and compliance to the service, and, vice versa, as an actor who could benefit from the envisaged service. In turn, this reframing introduced a solution in which patient and doctor could devise new therapies with other medical specialists by mediation of the startup's service. The designer mentions in the written reflections: "I lost a lot of time by trying to set a research with users again. In the back of my head, I knew the evaluation with patients was probably not going to be very successful or insightful, and that instead, my concepts were lacking a whole different route of knowledge: the experience of medical specialists".

\section{DISCUSSION AND CONCLUSION}

The case study highlights the notion of activity awareness and its importance for framing within DSI. Moreover, prior to the reframing, our data shows that the designer was experiencing a tunnel vision by limiting himself to the frame from the client's initial briefing. Later however, the designer decides to include the doctor (D) in his framing and makes use of the potential that this actor could bring in relation to the patient (P) and the digital service (DS). Prior, the doctor was only a sales channel, and the co-reflections with patients $(\mathrm{P})$ opened the designer to see a new potential for doctors (D). This move allowed the service to become self-organized and introduces new possibilities for other actors to connect to the DSI, moving the design towards a shareable solution. Activity awareness made the designer thoughtful to how his design may impact and relate to different activities and motives of network actors.

Our novel approach to understanding framing within a DSI provided a view into how a designer frames and makes moves, using the relationships in and between different activity systems. A first rough estimate of interrater reliability shows that there is a difference in the amount of activity systems that raters recognize in (visual) data, but that there is high agreement on which activity system is seen. Additional studies should provide more robustness to our approach of framing in relation to CHAT.

The designer's research in this case study primarily made use of a process of co-reflection, which stimulated activity awareness. Co-reflection allows for the exploration of deeper meanings, and appreciation of the history and relations within and between activity systems. This approach helped the designer to critically reflect and reframe the project by looking at cultural-historical values between a current and newly devised digital service. As a result, the service interfaces for the DSI was designed in such a way that many actors would find and organize for value in the DSI, according to their own object-oriented activities. Still, even within the approach co-reflection, working with multiple activity systems simultaneously proved difficult for the designer. To accommodate for complexity in DSI, we need to include theories like CHAT that help designers map out, share, and construct their understanding of relational complexity within and between activity systems.

\section{REFERENCES}

Akin, Ö. (2001), "Variants in design cognition”, In: Design knowing and learning: Cognition in design education, Elsevier Science pp. 105-124. https://doi.org/10.1016/B978-008043868-9/50006-1

Baha, S.E. (2010), Designing for and with Stakeholders, MSc thesis, Eindhoven University of Technology.

Baha, S.E., Dawdy, G., Sturkenboom, N., Price, R.A. and Snelders, H.M.J.J. (2018), “Good Design-Driven Innovation", Design Research Society International Conference, Limerick, 25-28 June, University of Limerick, Limerick, Ireland, pp. (98-111). http:/doi.org/10.21606/dma.2017.648.

Barrett, M., Davidson, E., Prabhu, J. and Vargo, S.L. (2015), "Service innovation in the digital age: key contributions and future directions”, MIS Quarterly, Vol. 39 No. 1, pp. 135-154. https://doi.org/10.25300/MISQ/2015/39:1.03

Boland Jr, R.J., Lyytinen, K. and Yoo, Y. (2007), "Wakes of innovation in project networks: The case of digital 3-D representations in architecture, engineering, and construction”, Organization Science, Vol. 18 No. 4 , pp. 631-647. https://doi.org/10.1287/orsc.1070.0304

Calabretta, G. and Kleinsmann, M. (2017), “Technology-driven evolution of design practices: envisioning the role of design in the digital era". Journal of Marketing Management, Vol. 33 No.3-4, pp. 292-304. https://doi.org/10.1080/0267257X.2017.1284436

Carroll, J.M., Rosson, M.B., Convertino, G. and Ganoe, C.H. (2006), “Awareness and teamwork in computersupported collaborations", Interacting with Computers, Vol. 18, pp. 21-46. https://doi.org/10.1016/j.intcom.2005.05.005 
Creswell, J.W., (2012), Educational research. Planning, conducting, and evaluating quantitative and qualitative research, Pearson, Boston.

Cross, N. (2001), "Design cognition: Results from protocol and other empirical studies of design activity", In: Design knowing and learning: Cognition in design education, pp. 79-103. Elsevier Science. https://doi.org/10.1016/B978-008043868-9/50005-X

Cross, N. (2007), Designerly ways of knowing, Birkhauser, Basel, Switzerland.

Dorst, K. (1997), Describing design: a comparison of paradigms, $\mathrm{PhD}$ thesis, Delft University of Technology.

Dorst, K. and Cross, N. (2001), "Creativity in the design process: co-evolution of problem-solution", Design Studies, Vol. 22 No. 5, pp. 425-437. https://doi.org/10.1016/S0142-694X(01)00009-6

Dorst, K. (2011), “The core of 'design thinking' and its application”, Design Studies, Vol. 32 No. 6, pp. 521532. https://doi.org/10.1016/j.destud.2011.07.006

Dorst, K. (2015), Frame Innovation: Create new thinking by design, MIT Press, London.

Engeström, Y. (2014), Learning by expanding, Cambridge University Press, New York.

Goldschmidt, G. (1991), "The dialectics of sketching”, Creativity Research Journal, Vol. 4 No. 2, pp. $123-143$. https://doi.org/10.1080/10400419109534381

Hey, J.H.G. (2008). Effective framing in design, PhD Thesis, University of California.

Kaptelinin, V. and Nardi, B. A. (2009), Acting with Technology: Activity Theory and Interaction Design. The MIT Press.

Kaptelinin, V. and Uden, L. (2012), "Understanding delegated actions: Toward an activity- theoretical perspective on customer-centered service design”, Service Design and Innovation Conference, Espoo, Finland, 8-10 February, Linköping University Electronic Press, Linköping, Sweden, pp. (101-109).

Kimbell, L. and Blomberg, J. (2017), “The object of service design”, In: Designing for Service: Key Issues and New Directions. Bloomsbury, London, pp. 81-94.

Kleinsmann, M.S. (2006), Understanding collaborative design, $\mathrm{PhD}$ Thesis, Delft University of Technology.

Kleinsmann, M.S. and Snelders, H.M.J.J. (2015), "Reconceptualizing design thinking and equipping designers for the next wave of digital innovation", International Conference on Engineering Design (ICED 15), The Design Society, Milano, Italy, 27-30 July, pp. (557-564).

Lloyd, P., Lawson, B. and Scott, P. (1995), “Can concurrent verbalization reveal design cognition?”, Design Studies, Vol. 16 No. 2, pp. 237-259. https://doi.org/10.1016/0142-694X(94)00011-2

Maffei, S. and Sangiorgi, D. (2006), "From communication design to activity design", In: Designing Effective Communications: Creating Contexts for Clarity and Meaning, Allworth Press, New York, pp. 83-100.

Menichinelli, M. (2018), "Service design and activity theory for the meta-design of collaborative design processes", Service Design and Innovation Conference, Milano, Italy, 18-20 June, Linköping University Electronic Press, Linköping, Sweden, pp. (994-1008).

Schön, D.A. (1983), The reflective practitioner: how professionals think in action, Basic Books.

Schön, D.A. (1984), "The architectural studio as an exemplar of education for reflection-in-action", Journal of Architectural Education, Vol. 38 No. 1, pp. 2-9.

Schön, D.A. and Wiggins, G. (1992), "Kinds of seeing and their functions in designing”, Design studies, Vol. 13 No. 2, pp. 135-156. https://doi.org/10.1016/0142-694X(92)90268-F

Stumpf, S.C. and McDonnell, J.T. (2002), "Talking about team framing: using argumentation to analyse and support experiential learning in early design episodes”, Design studies, Vol. 23 No. 1, pp. 5-23. https://doi.org/10.1016/S0142-694X(01)00020-5

Stompff, G. (2012), Facilitating Team Cognition: How designers mirror what NPD teams do, PhD Thesis, Delft University of Technology.

Ten Bhömer, M. (2016), Designing embodied smart textile services: the role of prototypes for project, community and stakeholders, PhD thesis, Eindhoven University of Technology.

Tiwana, A., Konsynski, B. and Bush, A.A. (2010), "Research commentary-Platform evolution: Coevolution of platform architecture, governance, and environmental dynamics", Information systems research, Vol. 21 No. 4, pp. 675-687. https://doi.org/10.1287/isre.1100.0323

Valkenburg, R. (2000), The Reflective Practice in product design teams, PhD Thesis, Delft University of Technology.

Valkenburg, R. and Dorst, K. (1998), “The reflective practice of design teams”, Design studies, Vol. 19 No. 3 , pp. 249-271. https://doi.org/10.1016/S0142-694X(98)00011-8

Vygotsky, L.S. (1978), Mind in society (Cole, M., John-Steiner, V., Scribner, S. and Souberman, E., Eds.), Harvard University Press, MA, Cambridge.

Yoo, Y., Boland Jr, R.J., Lyytinen, K., and Majchrzak, A. (2012), “Organizing for innovation in the digitized world”, Organization science, Vol. 23 No.5, pp. 1398-1408.

Yukawa, J. (2006), "Co-reflection in online learning: Collaborative critical thinking as narrative", International Journal of Computer-Supported Collaborative Learning, Vol. 1 No.2, pp. 203-228. https://doi.org/10.1007/s11412-006-8994-9 